University of Wollongong

Research Online

SMART Infrastructure Facility - Papers

Faculty of Engineering and Information

Sciences

2017

Data mining in educational technology classroom research: Can it make a contribution?

Charoula Angeli

University of Cyprus

Sarah Katherine Howard

University of Wollongong, sahoward@uow.edu.au

Jun Ma

University of Wollongong, jma@uow.edu.au

Jie Yang

University of Wollongong, jiey@uow.edu.au

Paul A. Kirschner

Open Universiteit Nederland, paul.kirschner@ou.nl

Follow this and additional works at: https://ro.uow.edu.au/smartpapers

Part of the Engineering Commons, and the Physical Sciences and Mathematics Commons

Research Online is the open access institutional repository for the University of Wollongong. For further information contact the UOW Library: research-pubs@uow.edu.au 


\title{
Data mining in educational technology classroom research: Can it make a contribution?
}

\begin{abstract}
The paper addresses and explains some of the key questions about the use of data mining in educational technology classroom research. Two examples of use of data mining techniques, namely, association rules mining and fuzzy representations are presented, from a study conducted in Europe and another in Australia. Both of these studies examine student learning, behaviors, and experiences within computersupported classroom activities. In the first study, the technique of association rules mining was used to understand better how learners with different cognitive types interacted with a simulation to solve a problem. Association rules mining was found to be a useful method for obtaining reliable data about learners' use of the simulation and their performance with it. The study illustrates how data mining can be used to advance educational software evaluation practices in the field of educational technology. In the second study, the technique of fuzzy representations was employed to inductively explore questionnaire data. The study provides a good example of how educational technologists can use data mining for guiding and monitoring school-based technology integration efforts. Based on the outcomes, the implications of the study are discussed in terms of the need to develop educational data mining tools that can display results, information, explanations, comments, and recommendations in meaningful ways to non-expert users in data mining. Lastly, issues related to data privacy are addressed.
\end{abstract}

\section{Keywords}

technology, make, educational, can, mining, data, research:, contribution?, classroom

\section{Disciplines}

Engineering | Physical Sciences and Mathematics

\section{Publication Details}

Angeli, C., Howard, S. K., Ma, J., Yang, J. \& Kirschner, P. A. (2017). Data mining in educational technology classroom research: Can it make a contribution?. Computers and Education, 113 226-242. 


\title{
Data Mining in Educational Technology Classroom Research: Can it Make a Contribution?
}

\begin{abstract}
The paper aims to address and explain some of the key questions about the use of data mining in educational technology classroom research. Two examples of use of data mining techniques, namely, association rules mining and fuzzy representations are presented, from a study conducted in Europe and another in Australia. Both of these studies examine student learning, behaviors, and experiences within computer-supported classroom activities. The results provide adequate understanding of students' interactions with technology, and reveal patterns demonstrating distinct differences in students' learning experiences. The significance of data mining techniques in terms of answering research questions that cannot be easily addressed by traditional statistical techniques is demonstrated. Implications for learning design are addressed, and considerations for wider application of data mining in educational technology research are discussed.
\end{abstract}

Keywords: Educational data mining, educational technology research, association rules mining, fuzzy representations. 


\section{Data Mining in Educational Technology Classroom Research: Can it Make a Contribution?}

\section{Introduction}

Data mining has long been used in marketing, advertising, health, engineering, and information systems. At its core, data mining is an inductive, analytic, and exploratory approach, which is concerned with knowledge discovery through identification of patterns within large sets of data. In the last 10 years, the field of Educational Data Mining (EDM) has emerged as a distinct area of research concerned with using data mining techniques to answer educational questions, such as, "What are the difficulties students encounter during a learning activity?”, “What sequences of computer interactions lead to successful problem-solving performance?”, and "What sequences of actions characterize high performers and low performers in problemsolving activity?” EDM can also provide new insights into “wicked” educational problems, such as, "What are differences in ways students experience learning," and "How can learning designs account for variations in students’ learning experiences?”

In particular, EDM is concerned with developing methods for analyzing data from educational settings in order to improve the teaching and learning process (Romero \& Ventura, 2007; Ingram, 1999). Succinctly, data mining techniques have been mostly used within the context of web-based or e-learning education in order to: (a) suggest activities, resources, learning paths, and tasks for improving learners’ performance and adapting learning experience (Tang \& McCalla, 2005); (b) provide feedback to teachers and instructional designers in regards to learners' difficulties with the content and structure of a course, so that revisions can be made 
to facilitate students' learning (Merceron \& Yacef, 2004; Zaiane \& Luo, 2011); (c) predict learners’ performance (Ming \& Ming, 2012); and (d) inform administrators about the effectiveness of instructional programs, so that better planning and allocation of human and material resources can be achieved (Romero \& Ventura, 2007).

Based on a number of reviews and meta-analyses published (Mohamad \& Tasir, 2013; Romero \& Ventura, 2007; Romero \& Ventura, 2010; Baker \& Yacef, 2009), the most popular data mining techniques include: (a) clustering (He, 2013; Perera, Kay, Koprinska, Yacef, \& Zaiane, 2009; Beal, Qu, \& Lee, 2006; Amershi \& Conati, 2009); (b) regression (Carmona, Castillo, \& Millan, 2007; Ming \& Ming, 2012); (c) association rules mining (Lin, Alvarez, \& Ruiz, 2002); and (d) sequential pattern mining (Perera et al., 2009). In clustering, the goal is to split the data into clusters, such that, there is homogeneity within clusters and heterogeneity between clusters (Baker \& Siemens, 2014). In educational research, clustering procedures have been used to find patterns of effective problem-solving strategies in exploratory computer-based learning environments (He, 2012; Beal, Qu, \& Lee, 2006; Amershi \& Conati, 2009). In regression, the goal is to develop a model that can infer or predict something about a data set. In regression analyses, a variable is identified as the predicted variable and a set of other variables as the predictors (similar to dependent and independent variables in traditional statistical analyses) (Baker \& Siemens, 2014). In association rules mining, the goal is to extract rules of the form if-then, such that if some set of variable values is found, another variable will generally have a specific value (Baker $\&$ Siemens, 2014). In sequential pattern mining, the aim is to find temporal associations between events to determine what path of student behaviors led to a successful group project (Perera et al., 2009). 
Currently, most work on data mining has at its base a computer science rather than educational perspective. Within the educational domain, data mining techniques have been mostly used in e-learning/web-based research, because of the ease of accessing student log data and performing automatic analyses of the data. There is, however, also a need to investigate the uses of EDM in real classrooms in order to better understand students' interaction with technology as well as the complexities entailed in investigating how students with diverse needs and cognitive characteristics perform with technology in real classroom settings. The issue then becomes whether EDM can make a contribution to educational technology classroom research in terms of providing tools and techniques that educational technology researchers can easily grasp and apply to their own research in order to answer research questions that cannot be easily answered by traditional statistical techniques.

In view of that, in this paper, the authors, within the context of two different studies, describe their efforts in using data mining procedures in educational technology classroom research and identify difficulties in applying data mining techniques and tools in this research context. The first study was carried out in a European country and sought to investigate how field-dependent and field-independent learners solved a problem using a simulation tool. For the purposes of the first study, the authors used a sequence, association, and link analysis for capturing and analyzing learners' interactions with the simulation tool. This analysis provided a detailed and analytic description of the differences in field-dependent and field-independent learners' problem-solving process, providing at the same time clear understanding of fielddependent learners' difficulties to take full advantage of the affordances of the simulation in order to maximize learning benefits. 
The second study addresses the use of educational technology in Australian secondary schools. The research considers variations in student experiences in an integrated learning environment and how this may relate to learning. The aim of the study was to better understand the range of students' experiences to inform teachers' integrated learning designs, so that all students could engage in learning through digital technologies. Considering the complexity of the learning environment and large number of key factors affecting students' experiences in the classroom, association rules mining and fuzzy representations were used to explore relations among students' questionnaire responses and national assessment outcomes. The results showed significantly different patterns of key technology integration factors relating to literacy and numeracy outcomes. The findings provide guidance for learning design in relation to how teachers may provide different experiences in technology-integrated learning to support all learners.

In the general discussion section of this paper, the authors discuss the contribution of data mining in educational technology classroom research, within the context of the two studies, while at the same time they also consider obstacles related to the intrinsic difficulty associated with learning how to use data mining tools and apply EDM techniques to educational data. Research directions aiming at making data mining tools and techniques more accessible to educational researchers are addressed.

\section{Study 1}

\section{Theoretical framework and research questions}

In the first study, the authors used a data mining technique called sequence, association, and link analysis to understand and best describe how the cognitive style of field dependence- 
independence (FD-I) affected undergraduate students' ability to solve a problem using a glassbox simulation. Glass-box simulations are tools that promote explorative modeling; that is, they allow students to test or explore models, but not to create their own models or modify existing ones (Clariana \& Strobel, 2008). According to Landriscina (2013), simulations are distinguished into black-box or model-opaque simulations, and, glass-box or model-transparent simulations. In black-box or model-opaque simulations learners explore a system's behavior, but the underlying conceptual and computational model of the simulation remains hidden. Thus, learners can only observe the results of the causal relationships between the variables (Landriscina, 2013). Glassbox or model-transparent simulations, on the other hand, make the structure of the model underlying the simulation visible to the learners in the form of a diagram with nodes and connecting links between them (Landriscina, 2013).

FD-I is a cognitive style directly related to how humans perceive, organize, and process information (Witkin, Moore, Goodenough, \& Cox, 1977; Morgan, 1997; Price, 2004). It is distinguished from learning styles, in that learning styles are subjective accounts of individuals' instructional preferences across specific domains and tasks (Messick, 1987). FD-I was defined by Witkin et al. (1977) as "the extent to which a person perceives part of a field as discreet from the surrounding field as a whole, rather than embedded in the field; or the extent to which the organization of the prevailing field determines perception of its components; or, to put it in everyday terminology, the extent to which the person perceives analytically" (pp. 6-7). Witkin et al. (1977) conceptualized FD-I as a construct with two discrete modes of perception, namely, field dependence and field independence. At the one extreme end, perception is dominated by the prevailing field and is designated as field dependent (FD). At the other end, perception is more or less separate from the surrounding field, and is designated as field independent (FI). 
Contemporary research studies have examined the effects of learning with glass-box (model-transparent) simulations on FI and FD learners' performance, and, found that FI learners outperformed FD learners during problem solving with this type of simulation (Author; Burnett, 2010; Dragon, 2009). However, these investigations have primarily focused on identifying quantitative differences in performance between FD and FI learners without providing detailed information about FD and FI learners' interactions with the simulation as well as related difficulties that learners encountered during the problem-solving process with the simulation. While quantitative investigations are in general useful, they do not provide enough insight about how to help those learners, such as for example FD learners, who usually encounter problems during problem solving and need to be supported by the teacher so they can also have successful learning experiences with technology.

Therefore, given the limitations of the existing body of research on FD and FI learners' problem solving with simulations, the present study applied sequence, association and link analyses in order to assess and compare FD and FI learners' interactions with a glass-box simulation within the context of solving a problem about immigration policy. The research purpose of the study was to identify sequences of interactions with the simulation that were associated with successful performance and whether those sequences of interactions differed between FD and FI learners. Analytically, the research questions were stated as follows:

1. What sequences of interactions with the simulation lead to successful problem-solving performance?

2. How do the sequences of interactions with the simulation differ between FD and FI learners?

3. What are the learning difficulties that FD learners encounter during the problem-solving process with the simulation? 
Evidently, traditional statistical techniques cannot provide the means for providing answers to these questions, and, thus, the issue becomes whether data mining, and in particular the sequence, association and link analysis that was employed here, can answer these questions in informative and useful ways for the educational technology researchers.

\section{Method}

\section{Participants}

One hundred and fifteen freshmen from a teacher education department were recruited to participate in the study. Students were initially screened based on their scores on the Hidden Figures Test (HFT; French, Ekstrom, \& Price, 1963). The HFT was used for identifying students' FD-I. The highest possible score on the HFT is 32 and the lowest zero. In accordance with other research studies (Chen \& Macredie, 2004; Daniels \& Moore, 2000; Khine, 1996), the cut-off points for this study were set to two levels of FD-I, namely FD and FI. Students with scores 18 or lower on the HFT were classified as FD learners, while students who scored 19 or higher were classified as FI. Of the 115 students, 45 of them were found to be FI learners, and the remaining $70 \mathrm{FD}$. Of the 115 participants, 94 (82\%) were females, and 21 (18\%) males. The average age of the participants was 17.86 years $(S D=.45)$. All students had basic computing skills, but no prior experience with problem solving with simulations.

\section{The simulation task}

All research participants were asked to interact with a glass-box simulation that was specifically developed for the purposes of this study, in order to solve a problem about immigration policy. The researchers explained to the participants that nowadays a lot of people 
move from one country to another in search of a better life for their children and themselves. Students were given a scenario about people from country A, who wanted to move to country B due to a high unemployment rate in country A. Students had to interact with the simulation in order to test hypotheses and decide about whether and under what conditions country B could accept immigrants from country A.

The underlying model of the glass-box simulation is depicted in Figure 1. Accordingly, the model shows how an increase in the number of births in country A will cause an increase in the population of country A. This, in turn, and provided that not enough employment opportunities are created in the interim to cover the new demands for employment in country A, will eventually lead to an increase in the unemployment rate of country A. In contrast, an increase in the number of deaths in country A will eventually cause a decrease in the unemployment rate of country A. In the case of an increase in the unemployment rate of country A, people from country A will eventually seek employment in another country - country B. A movement of people from country A to country B will eventually cause an increase in the unemployment rate of country B, if country B does not create in the meantime enough employment opportunities to cover the increased demand for employment. The model shows how an increase in the number of businesses in country B will cause a decrease in country's B unemployment rate, while a movement of businesses from country B to A will cause a decrease in country's A unemployment rate, but in the long run a possible increase in country's B unemployment rate. In total, the tool simulated the phenomenon of immigration using five independent variables, namely number of births in country A, number of births in country B, number of deaths in country A, number of deaths in country B, and movement of businesses from country B to country A. The students had to change the values of the independent variables 
one at a time to observe the effects on the dependent variables in order to decide, and, propose in writing if and under what conditions country B could possibly accept immigrants from country A.

\section{---Insert Figure 1 about here---}

When the learners run the model the simulation opens a meter for each dependent and independent variable. As shown in Figure 2, each meter displays the initial value of each variable and the range of values it can take. At each run time, the learner can change the value of one independent variable at a time and observe how the meters of the affected dependent variables change.

\section{---Insert Figure 2 about here---}

\section{Research instruments}

Hidden Figures Test

The Hidden Figures Test (HFT) was administered to classify the research participants in FD and FI learners (French, Ekstrom, \& Price, 1963). The test is divided into two parts, and each part contains 16 questions. The time allotted for answering each part is 12 minutes. The scores on the HFT range from 0 to 32. Basically, each question on the HFT presents five simple geometric figures and a more complex one. Students are instructed to discover which one of the five simpler figures is embedded in the more complex one. According to Rittschof (2010), the HFT is the most reliable and widely used test for measuring FD/I. It is also highly correlated with the Group Embedded Figures Test $(r=.67$ - .88), another popular test for determining FD/I (Witkin, Oltman, Raskin, \& Karp, 1971). 


\section{Assessment rubric}

The quality of learners’ written answers to the immigration problem were assessed with a rubric that was inductively constructed for the purposes of this study. The scoring rubric assessed three levels of quality ranging from 1 (poor quality) to 3 (high quality). The specific criteria for each level are shown in Table 1. Two independent raters evaluated students' answers to the immigration problem, and Cohen's kappa was used to measure interrater reliability. A satisfactory interrater reliability of $k=0.87$ was computed, while noted discrepancies between the two raters were resolved after discussion.

\section{---Insert Table 1 about here---}

\section{Research procedures}

During the first 25-min research session the researchers administered the HFT in order to determine learners’ field type. In a follow-up 60-min session, the researchers demonstrated a glass-box simulation, different than the one that was used for collecting research data for this study, and showed how to use it in order to solve a problem. The students were given 40 min to interact with the simulation individually in order to explore different problem-solving scenarios and learn how to control one independent variable at a time. The researchers explicitly explained the difference between dependent and independent variables, and, demonstrated how changes in the independent variables affected the dependent variables. The actual research data that were used in the analyses of this study were collected during the last 60-min session. 


\section{Data structure and analysis}

The students' interactions with the simulation were captured into video files with River Past Screen Recorder, a screen capturing software. Each video file had an average duration of 50 minutes long and a size of about 4GB. A scheme was used for coding learners' interactions in the form of a log file, which took the form of a table with three columns including Student_ID, Time, and Action. Student_ID referred to students’ research id number, Time denoted the start/end time of an event, and Action described what the interaction entailed in the form of a sequence of computer actions. The total number of entries in this table, which constituted the data for the data mining analysis, was 4570 entries. Regarding the Action field in the data table, the simulation afforded five computer actions that the students could employ in order to explore the relationships between all dependent and independent variables, as depicted in Figure 1, in order to decide if and under what conditions country B could accept immigrants from country A. The first action was about displaying all variables and the relationships amongst them, as represented in the model shown in Figure 1. The second, was about using the test tools in order to run the simulation. The third was about opening the meter of each variable so the students could change the values of the independent variables while observing at the same time the effects on the dependent variables. The fourth was to use the play button, which was one of the test tools, to actually play the simulation, and lastly, the stop button for stopping the simulation. Thus, the following computer interactions were coded: $\boldsymbol{B}$ for viewing all simulation variables and the relationships between them; $\boldsymbol{T}$ for accessing the test tools needed for a simulation test; $\boldsymbol{M}$ for opening the meter of each variable; $\boldsymbol{P}$ for running/playing the simulation; and $\boldsymbol{S}$ for terminating/stopping the simulation. Additionally, the codes IV1, IV2, IV3, IV4, and IV5 were used for denoting each one of the five independent variables the students had to control. 
A Sequence, Association, and Link analysis (Nisbet, Elder, \& Miner, 2009) was used in order to identify unique differences between the FD and FI learners. Specifically, the sequence, association and link analysis was used for extracting association rules in order to determine which simulation actions were closely associated together. The technique was also used for extracting an immediate subsequent action given a previous one, and for mining patterns of interaction between individuals of different field type and computer actions. In association rule mining, relationships and patterns are expressed in the form of an association rule:

$$
\text { If } A \text { then (likely) } C
$$

Each rule includes an antecedent (A) and a consequent (C). This can be understood as "IF A then C." Rules may contain single or multiple antecedents and consequents, such as "IF A and B, then C.” The importance of a rule is determined through critical measurements: support, confidence and lift (Tan, Kuman, \& Srivastava, 2004; Han, Kamber, \& Pei, 2012). The extent to which the antecedent(s) and consequent(s) occur simultaneously in the dataset is indicated through support. The extent to which the consequent(s) occur(s) given the antecedent(s) is indicated through confidence. The correlation between the antecedent(s) and consequent(s) is indicated through lift. Lift can be used to estimate prediction performance. For the two sequence, association, and link analyses that were performed, the minimum support was set to 0.55 and the confidence level to 0.95 .

\section{Results and discussion}

The quality of FD learners' answers to the immigration problem was found to be 1.43 $(S D=.63)$, while the quality of FI learners' answers was found to be $2.10(S D=.75)$. The time 
FD and FI learners spent with the simulation was also measured and no significant differences were found between the two groups of participants. The large mean difference in the quality of FD and FI learners' answers was further investigated using a one-way analysis of variance (ANOVA), and was found to be statistically significant, $F(1,114)=12.06, p<0.05, n^{2}=0.17$, in favour of the FI learners.

In order to further investigate how FD and FI learners interacted with the simulation in order to solve the problem, a separate sequence, association, and link analysis was carried out for each group of FD and FI learners. The outcomes of the sequence, association, and link analyses are shown in Tables 2 and 3 for the FD learners, and, Tables 4 and 5 for the FI learners.

According to Table 2, FD learners failed to engage in systematic hypotheses testing using the simulation in order to collect data and propose a solution to the problem. This is easily confirmed by the lack of association rules related to controlling the variables IV3, IV4, and IV5, and, the very limited activity about controlling the variables IV1 and IV2. As shown in Table 2, IV1 and IV2 were the only independent variables that FD learners controlled, ignoring the effects of the other three independent variables on the dependent variables. Interestingly, as it is shown in Table 3, which shows the frequencies of each rule for the FD learners, the datasets of the rules associated with controlling IV1 appear 46 times, and 39 times for IV2, indicating a significant lack of activity related to the control of independent variables if one considers the fact that there were 70 FD learners participating in the study. This implies that not all FD learners were able to control IV1 or IV2, and none was able to control all of the five independent variables. This, subsequently, led to answers of poor quality. In addition, FD learners' computer interactions, appeared to be repetitions of the same sequences or slightly different sequences of incomplete actions that did not allow the FD learners to collect useful data for solving the 
problem. These actions indicate FD learners' uncertainty of what they needed to do to test the model, as well as lack of knowledge in regards to controlling variables and testing hypotheses. All in all, the association rules in Table 2 and Table 3 reveal FD learners' weakness to adequately investigate the immigration problem with the glass-box simulation.

\section{---Insert Table 2 about here--- \\ ---Insert Table 3 about here---}

In contrast with the rules shown in Table 2, the rules in Table 4 show that the FI learners interacted with the simulation in a systematic way through a sequence of meaningful actions that led to successful interpretations of the simulation outcomes of the glass-box simulation and reported answers of high quality. According to the rules shown in Table 4, the FI learners followed all necessary steps in order to properly control all five independent variables, collect data, and form conclusions. What is more, according to Table 4, FI learners also engaged in actions demonstrating attempts for examining the effects of several combinations of any two or three independent variables. These actions illustrate FI learners' ability to plan more advanced experimental investigations. Additionally, as it is shown in Table 5, which shows the frequencies of each rule for the FI learners, the datasets associated with controlling the independent variables appear 45 times for each independent variable and 30 times for any combination of independent variables. These data show significant differences between FD and FI in regards to their investigations with the glass-box simulation.

\section{---Insert Table 4 about here---}




\section{---Insert Table 5 about here---}

\section{Conclusions from Study 1}

The results from the first study in this paper showed that FD learners were not able to use the simulation in order to control variables, collect useful data, and form appropriate conclusions. Obviously, the FD learners were not able to cope with the complexity of the task and failed to develop a step-by-step strategy for solving the problem. In contrast, the FI learners handled successfully the complexity of the problem-solving space, carefully examined the effects of each independent variable on the dependent variables, and decided accordingly. The frequencies of the rules of the FD and FI learners (Tables 3 and 5) show important differences between the two types of learners in terms of how they used the simulation to investigate the problem at hand, and, reach an informed decision. All in all, the FD learners failed to collect useful data with the simulation, as the rules in Table 2 strongly indicate, and failed thereafter to write an informed answer for the immigration problem.

Therefore, based on the findings of the first study, data mining can make a contribution to educational technology research in regards to better understanding how learners of different cognitive types interact with a technology tool to solve a problem. As mentioned previously, the data file that was analyzed using the sequence, analysis, and link technique included 4570 entries describing learners' chronological interactions with the simulation, and, undoubtedly, traditional statistical techniques could not possibly investigate patterns of association among all 4570 entries efficiently. Thus, association rules mining is a useful technique for the educational technology researchers who are interested in improving the instructional design of educational software in order to maximize the learning benefits for all learners, irrespective of field type. 
Specifically, the data from the study here strongly indicated that FD learners failed to investigate the immigration problem, which entailed understanding and investigation of the multiple relationships between the underlying variables, and synthesis of data for the extraction of useful information in order to reach an informed solution for the problem at hand. Thus, evidently, association rules mining in this research context constituted a useful technique for identifying FD learners' difficulties, and, subsequently, useful for guiding future efforts about improving the design of the simulation by possibly adding embedded software scaffolds in order to facilitate and assist FD learners' investigations with the simulation. Hence, for this line of educational technology research, data mining can make a contribution.

\section{Study 2}

\section{Theoretical framework and research questions}

In the second study, the authors conducted a preliminary exploratory examination of important technology integration factors and their relation to learning. In education, a common misconception is that young people are confident users of digital technologies, and that use of digital technologies will be motivating in learning and lead to positive learning outcomes (Author; Margaryan, Littlejohn, \& Vojt, 2011; Selwyn, 2009; Thompson, 2013). However, research has shown that many students are, in fact, not confident using or engaged with technology (e.g., Wang, Hsu, Campbell, Coster, \& Longhurst, 2014; Warschauer \& Matuchniak, 2010), which suggests a more varied range of student experiences in technology-integrated learning and a more complex relationship with student performance. If difference in perceptions of learning between teachers and students is too large, there is a risk of students becoming unengaged and struggling to learning (Vermunt \& Verloop, 1999). Therefore, a better 
understanding of student experiences using digital technologies, and what this means for learning, is needed to develop more effective and inclusive learning environments (Könings, Seidel, \& van Merriënboer, 2014; Li, 2007; Pellas, 2014; Skryabin, Zhang, Liu, \& Zhang, 2015). In essence, the second study directly addresses the complexity of technology integration, which according to Borko, Whitcomb, and Liston (2009), has proven to be a "wicked" problem for educational research. One of the reasons for this is because "orderly processes in creating human judgment and intuition lead people to wrong decisions when faced with complex and highly interacting systems” (Forrester, 1971, p. 52). Primarily, it is nearly impossible for the human mind to fully conceptualize complex systems, such as teaching and learning, and to fully understand dynamic relations and feedback among constituent parts (Author). Data mining can provide new insights into the important relations and interactions among known key factors of technology integration. The knowledge discovery approach of data mining techniques is able to account for numerous factors and complex systems (Fayyad, Piatestsky-Sharpiro, \& Smyth, 1996), and findings from these new approaches can inform and extend the existing body of knowledge (Baker, 2010).

Therefore, in this study the authors argue that students' different experiences in technology-integrated learning environments affect learning performance in different ways. The study was undertaken to examine which factors of students' technology integration, such as positive and negative engagement, and high and low confidence in using digital technologies were meaningfully related to learning outcomes. In particular, eight key factors of digital technology use, engagement with digital technologies, school engagement, and national assessments were explored. The analysis focused on two novel patterns including Information and Communication Technologies (ICTs) Engagement, Computer-Efficacy, and School 
Engagement, in relation to aggregated school-level performance on numeracy and literacy assessments. The specific research questions were stated as follows:

1. What are different patterns occurring among key factors relating to students' experiences in technology integration?

2. How do these patterns relate to learning outcomes?

\section{Method}

\section{Data sources}

The datasets used in this analysis were taken from a large-scale study examining the Australian Digital Education Revolution in New South Wales (DER-NSW), and from the Australian National Assessment Program Literacy and Numeracy (NAPLAN) assessments. The DER-NSW was a federal program (2008-2014) aiming to provide all secondary (Years 9-12) students and teachers with current and up-to-date digital technologies (Department of Education Employment and Workplace Relations, 2012). In New South Wales (NSW), the program was evaluated over four years (2010-2013) through online questionnaires and school case studies. A full description of the study can be found in Author (2013). The DER-NSW study included all government secondary schools across the state $(N=436)$. The analysis presented in this paper is drawn from the 2012 Year 9 student questionnaire data. Of the approximately 50,000 Year 9 students in NSW government schools, 21,795 (43\%) students completed a two-part questionnaire in 2012; 12,978 students completed Part A and 8,817 students completed Part B. Responses to Part B of the questionnaire were included in the current analysis. These data included students from 216 NSW secondary schools. 
The Australian NAPLAN assessment is administered to students each year, in school Years 3, 5, 7 and 9. The aim of the assessment is to test the types of skills that are essential for every child to progress through school and life (National Assessment Program, 2013). In each year, student's performance on reading, writing, spelling, grammar, punctuation and numeracy are measured. In alternating years, a small group of schools have also been assessed on civics and citizenship, ICTs, and science literacy. These provide a national “snapshot” of performance in these areas. Tests are administered by each state, at individual schools, using national protocols. Test results at the school level are made publicly available through the mySchool.com website. For the current analysis, Reading and Numeracy scores for 195 of schools participating in the Year 92012 Student Part B questionnaire were included in the analysis.

\section{Data structure and analysis}

The DER-NSW Student questionnaire B, administered in 2012, comprised a total of 147 question items covering five main subscales: School Engagement, Computer Use, Your Learning, Your Subjects, and Your Intentions. The School Engagement subscale is adapted from the NSW DEC Student School Life Survey (SPL-SSL), which provides the department with student feedback on schools. The Program for International Student Assessment (PISA) ICT use and familiarity measure (OECD, 2006) was used as the basis for the Computer Use subscale. Items on frequency of use, confidence (computer-efficacy) in performing tasks using a computer, such as internet searches and data manipulation, were included. The Your Learning subscale addressing students’ learning preferences was adapted from the NSW SchoolMap Best Practices Statements (Department of Education and Training, 2002). Your Subjects addressed students’ perceptions of success in different subject areas (Lamont \& Maton, 2010). Your Intentions was a 
standard department measure considering students' intentions to leave school early, begin to work, or post-school study after graduation. The questionnaire was pilot tested in 2009 at three schools and revised. Reliability of the questionnaire was determined to be high for each subscale, ranging from Cronbach’s alpha .83 to .93 .

In regards to data mining techniques, the current study combined the well-proven association rules analysis and fuzzy representations to answer the research questions. Fuzzy representation techniques aim to describe uncertainties in concepts and perceptions using fuzzy set theory. Combining association rules analysis with fuzzy representations allows for addressing increased sensitivity to variation among participants' responses. An example of this is the use of the standard Likert-type item of "strongly agree,” "agree,” “disagree,” and "strongly disagree” as responses. These responses do not contain a clear scale of meaning and can be interpreted differently by different participants. Therefore, each response will actually represent a range of vagueness. A fuzzy concept can be expressed by a fuzzy set to cover possible meaningful scales in a response, within which each scale has a value (called membership degree) to indicate to what extent this scale can be described using the fuzzy concept. For example, we can describe a student’s learning performance as "Sound" or "Excellent” based on his/her NAPLAN score. Here, "Sound” or "Excellent” are fuzzy concepts defined on NAPLAN scores. Given a NAPLAN score, say 560, we can determine, for example, 0.8 to "Sound" and "0.4" to “Excellent”. Using fuzzy representations, we can have a better understanding of the collected data and have a tool to handle vagueness in these data.

Specifically, the analysis comprised of three main data mining steps: factor generation, fuzzy representation, and association rule mining (already explained in study 1). The first step focused on generating factors related to student's engagement, performance and ICT efficacy. 
This was the process of identifying key questions from the dataset and construct factors from them. Eight main factors from the questionnaire, covering 16 sub-factors, were constructed: Computer-Efficacy (3 sub-factors), ICT Engagement (3 sub-factors), Learning Preferences (3 sub-factors), Learning Beliefs (3 sub-factors), ICT and Learning Performance (1 sub-factor), School Engagement (1 sub-factor), Teacher Directed ICT Use Frequency (1 sub-factor), and ICT Importance in Subject Areas (1 sub-factor). The eight main factors and the two NAPLAN factors (Numeracy and Reading) are shown in Table 6.

In the second step, raw responses of all factors were rescored to create a fuzzy representation. For the questionnaire data, the fuzzy representation was conducted at the individual level and then aggregated to a school level in order to match the NAPLAN data, which were only available at the school level. In the process of constructing fuzzy representations, numeric data and categorical data were processed in different ways. If a factor was measured using numeric data, the median value of all individual students in a school was used as the school level value of that factor. If a factor was described as categorical data, the most occurred value of all individual students in the same school was used as the school level value of that factor. The Year 92012 questionnaire and Year 92012 NAPLAN datasets were linked by a national school code.

An example of a fuzzy representation is defining the fuzzy concept “frequent user” of ICT technology in teaching as frequent user $(h)=\left\{\begin{array}{ll}\frac{h}{3}, & h<3 \\ 1, & h \geq 3\end{array}\right.$ where $\mathrm{h}$ is the participant's hours of ICT use in a day. The more time a user spends on ICT use, the higher the membership degree. Hence, a user who spends 1 hour daily on using ICT in teaching will be treated as a "less 
frequent” user with a membership degree of 0.33 . Similarly, we can categorize a user as "less frequent user," "frequent user" and "much frequent user."

In the final step, the dataset was split into three datasets, i.e., all schools (Dataset 1), schools with positive ICT engagement (Dataset 2), and schools with negative ICT engagement (Dataset 3). Students' engagement with ICT was identified as a motivating factor in teachers' use of digital technologies (Ertmer, Ottenbreit-Leftwich, Sadik, Sendurur, \& Sendurur, 2010). An association rules analysis was conducted on the three datasets to identify where potential significant relationships among factors may exist. The apriori algorithm in R was used to implement the association rule mining and adjustable parameters (support degree, confidence degree, and lift) were set and tuned. Rules from the three datasets were converted to a directed graph, in which each factor from the antecedent and consequent set was associated with a node in the graph. The stronger the connection, the thicker the arrow line.

\section{---Insert Table 6 about here---}

\section{Results and discussion}

Through association rules analysis, the factors that were found to be (a) important in both the positive and negative ICT Engagement datasets, and (b) related to students' computer use and beliefs, were selected for further examination. There were three ICT Engagement sub-factors with four measurements: ICT Engagement Positive, High (1); ICT Engagement Positive, Medium (2); ICT Engagement Positive, Low (3); ICT Engagement Neutral (4); ICT Engagement Negative, High (5). In more analytical terms, ICT Engagement Positive, High represented schools with students who agreed (Positive) with most engagement statements, and that 
agreement was strong (High). There were six Computer-efficacy factors: Computer-efficacy Productivity, No knowledge (6); Computer-efficacy Productivity, Low (7); Computer-efficacy Processing, No knowledge (8); Computer-efficacy Processing, Low (9); Computer-efficacy Creating, No knowledge (10); Computer-efficacy Creating, Low (11). Computer-efficacy factors described three types of increasingly complex computer tasks: Productivity (e.g., email, editing a document), Processing (e.g., making a simple presentation), and Creating (e.g., making a webpage). Scores were classified as: 'No knowledge’, Low, Medium, and High efficacy. Computer-efficacy Productivity, No Knowledge represented those students who selected 'I don't know what this means' (No Knowledge) on most of the productivity tasks. A 'Low' label represented students who understood most of the tasks, but needed help to perform them. A portion of students did report Medium and High computer-efficacy on all three task types, but rules containing these factors were not important in either dataset. There was one School Engagement factor, School Engagement, Negative (12), Neutral (13) and Positive (14). NAPLAN Reading, Medium (15) and Numeracy, Medium (16) were important in the datasets. The two factors were categorized into three levels: Low, Medium, and High, based on the schools' mean scores on each assessment.

The two directed graphs show the resulting patterns of rules for positive ICT Engagement (Dataset 2; see Figure 3) and negative ICT Engagement (Dataset 3; see Figure 4). The two graphs demonstrate how different patterns of factors that affected Reading and Numeracy have resulted depending on students’ engagement with ICTs.

\section{---Insert Figure 3 about here---}


In Figure 3, nine factors were important, forming 14 rules and two clusters with Reading and Numeracy at the center of each. An association did not exist between Reading (15) and Numeracy (16). All technology integration factors exhibited similar strengths in their associations with Reading and Numeracy, which suggests similar effects of those factors on learning performance in this group. Importantly, all of the computer-efficacy factors were No knowledge $(6,8$, and 10$)$. This suggests that the most frequently occurring rules were among schools where students were positive about using ICTs, but with limited knowledge on how to actually perform different tasks. School Engagement, Negative (12) also appears as an important factor in this dataset.

\section{---Insert Figure 4 about here---}

In Figure 4, nine factors were also important, forming 14 rules and two clusters with Reading (16) and Numeracy (15) at the center of each. Reading and Numeracy were also associated with each other. However, there were several key differences in patterns resulting from the two datasets. First, unlike positive ICT engagement, not all technology integration factors were equally related to Reading and Numeracy if students collectively reported negative ICT engagement. Where positive ICT Engagement (1-3) was also present, based on the fuzzy representations, it had a stronger effect on Reading and Literacy than Computer-efficacy factors (6, 8, and 10). This indicates that engagement would have stronger effects on learning performance in this group. Second, an important Computer-efficacy factor in this dataset was No Knowledge. This suggests that, similar to the positive group, the most frequently occurring rules were among schools where students were negative about using ICTs and did not feel confident about their knowledge to perform different computer-related tasks. School Engagement, Negative 
did not appear in the negative ICT engagement dataset, but the Neutral (13) factor did. This suggests that students who felt negatively about using ICTs in school, felt more positive about their schools.

\section{Conclusions from Study 2}

The results from the second study revealed significantly different patterns among factors affecting learning outcomes, depending on students’ engagement with ICTs. The findings showed that the same factors had different effects on learning outcomes, depending on students' engagement with digital technologies. The results provide a view of the complexity of and variation within students' experiences in technology-integrated learning, and shows that they are not homogenous. This finding extends and builds on other research studies, which showed that digital technologies are not necessarily engaging for all students, or that technology integration does not necessarily impact learning in positive ways (e.g., Margaryan, Littlejohn, \& Vojt, 2011; Wang, Hsu, Campbell, Coster, \& Longhurst, 2014; Warschauer \& Matuchniak, 2010).

The use of data mining techniques has provided a method to examine a large number of factors and complex associations amongst them in order to identify unique patterns, which may have otherwise been invisible or unconsidered (Cristobal, Romero, Ventura, Pechenizkiy, \& Baker, 2010). The use of fuzzy representations allowed for a deeper examination of known factors through the creation of categories, such as high, medium and low, providing this way a more nuanced analysis of associations. While this method exponentially increases the number of factors being analyzed, which can be problematic in traditional approaches, it is easily handled in data mining. As a result, in the current study, patterns observed between positive and negative 
ICT engagement and No knowledge computer-efficacy, as well as their different effects on learning outcomes, were identified and studied further.

In addition, by visualizing the results through directed graphs, the complexity of students' experiences in technology integration can be easily depicted. In addition, key points of interaction and effects can be isolated. The graphs not only provide a description of the relationships among factors, they also provide a way to compare variations within patterns. For example, in the current analysis, the students who positively engaged with ICTs were likely to have a lower computer efficacy. This finding is in contradiction to what is often assumed in technology integration, namely that positive engagement with ICT is related to higher confidence in performing technology-related tasks (Christoph, Goldhammer, Zylka, \& Hartig, 2015; Laird \& Kuh, 2005). Given that the use of digital technologies in the classroom is generally around internet research and word processing, students may not be given the chance to develop their knowledge of and experience using technologies. This may ultimately result in developing negative feelings or simply becoming uninterested in how ICTs can be used for learning purposes (Wang et al., 2014). However, the effect of computer-efficacy on learning outcomes was not as strong as the negative engagement in ICTs. In learning design, this suggests that time and resources could focus on engaging tasks, rather than up-skilling this group of students. This alludes to the belief that the use of digital technologies should be more complex and authentic to engage students (Ertmer et al., 2012). For schools where students had negative ICT engagement, computer-efficacy had less of an effect on Reading and Literacy, while the level of engagement was likely to have a stronger effect. Importantly, in this study, data mining techniques contributed significantly in answering the research questions through the identification of multiple patterns, which allowed the complexity of the learning environment to be observed. As 
a result, both researchers and teachers would be able to leverage findings to better understand some of complex effects of digital technologies on learning and inform learning design.

\section{General discussion and concluding remarks}

Based on the findings of the two studies discussed here, educational data mining can make a significant contribution to educational technology classroom research in terms of providing educational researchers with the tools to study teaching and learning. However, as it is also easily inferred from the analyses, employing data mining techniques can be a challenging endeavor raising some issues of concern. Specifically, the authors, based on their experiences as discussed in Study 1 and Study 2, group these issues into two main areas: (a) the structure and organization of the data for mining, and (b) the appropriateness of the data mining techniques.

In regards to data structure and organization, educational data sets often contain selfreported data (e.g., Study 2). Much of these data are usually collected through questionnaires, which often include a range of different types of questions with subjective answers. This issue becomes more complex when different forms of data, such as video (e.g., Study 1) and audio are introduced into the analysis. For data mining, these different data types need to be processed into a unified form that can be used for data mining. However, as current data mining techniques are not specifically developed for use with educational datasets, the preparation of classroom data for mining is often done manually by the researcher. This can be a difficult and extremely timeconsuming task highly prone, at the same time, to human error.

In regards to the second issue about selecting appropriate data mining techniques, the authors found it useful to experiment first with different techniques using different software tools before making a final decision. This was done because general-purpose data mining techniques 
are not specifically designed to answer educational questions, and, thus, may not always produce meaningful results with a specific educational dataset. For example, a high performance data mining technique used on one dataset may be inappropriate for another. One strategy the authors adopted for addressing this was to test and compare results from different data mining techniques before deciding on the techniques to use.

In conclusion, the authors herein recognize the added value of data mining techniques in opening up new ways of looking and analysing classroom data, and recognize at the same time the difficulty for the educational researchers to learn how to employ these techniques in their own research. Thus, for data mining to become mainstream in educational technology research, efforts need to be invested in developing new techniques or refining existing techniques to better meet the needs of educational research. This effort may require broad and sustained collaboration among researchers from various and multiple disciplines.

\section{References}

Author.

Author.

Amershi, S., \& Conati, C. (2009). Combining unsupervised and supervised machine learning to build user models for exploratory learning environments. Journal of Educational Data Mining, 1(1), 71-81.

Baker, R. S., \& Siemens, G. (2014). Educational data mining and learning analytics. In K. Sawyer (Ed.), Cambridge Handbook of the Learning Sciences (2nd edition, pp. 253-274). NY: Cambridge University Press. 
Baker, R. S., \& Yacef, K. (2009). The state of educational data mining in 2009: A review and future visions. Journal of Educational Data Mining, 1(1), 3-17.

Baker, R. S. (2010). Data mining for education. In International Encyclopedia of Education (pp. 112-118). NY: Elsevier.

Beal, C. R., Qu, L., \& Lee, H. (2006). Classifying learner engagement through integration of multiple data sources. Paper presented at the 21st National Conference on Artificial Intelligence (AAAI-2006), Boston, MA.

Borko, H., Whitcomb, J., \& Liston, D. (2009). Wicked problems and other thoughts on issues of technology and teacher learning. Journal of Teacher Education, 60(1), 3-7.

Bramer, M. (2007). Principles of data mining. London: Springer.

Chen, S. Y., \& Macredie, R. D. (2002). Cognitive styles and hypermedia navigation: Development of a learning model. Journal of the American society for information science and technology, 53(1), 3-15.

Christoph, G., Goldhammer, F., Zylka, J., \& Hartig, J. (2015). Adolescents’ computer performance: The role of self-concept and motivational aspects. Computers \& Education, $81,1-12$.

Clariana, B. R., \& Strobel, J. (2008). Modeling technologies. In J. M. Spector, D. M. Merrill, J. van Merrienboer, \& M. P. Driscoll (Eds.), Handbook of Research on Educational Communications and Technology (pp. 329 - 344). NY: Routledge.

Daniels, H. L., \& Moore, D. M. (2000). Interaction of cognitive style and learner control in a hypermedia environment. International Journal of Instructional Media, 27, 369-384. Department of Education and Training. (2002). SchoolMap Best Practices Statements. Sydney. Department of Education Employment and Workplace Relations. (2012). Digital Education 
Revolution - Overview. Digital Education Revolution - Overview. Retrieved September 20, 2013, from

http://www.deewr.gov.au/Schooling/DigitalEducationRevolution/Pages/default.aspx

Dragon, K. (2009). Field dependence and student achievement in technology based learning: A meta-analysis. Master thesis, University of Alberta, Alberta.

Ertmer, P. A., Ottenbreit-Leftwich, A. T., Sadik, O., Sendurur, E., \& Sendurur, P. (2012). Teacher beliefs and technology integration practices: A critical relationship. Computers \& Education, 59(2), 423-435.

Fayyad, U., Piatestsky-Sharpiro, G., \& Smyth, P. (1996). From data mining to knowledge discovery in databases. AI Magazine, 17(3), 37-54.

Forrester, J. W. (1971). Counterintuitive behaviour of social systems. Technology Review, 73(3), $52-68$.

French, J. W., Ekstrom, R. B., \& Price, L. A. (1963). Manual for kit of reference tests for cognitive factors. Princeton, NJ: Educational Testing Service.

He, W. (2013). Examining students' online interaction in a live video streaming environment using data mining and text mining. Computers in Human Behavior, 29(1), 90-102.

Ingram, A. (1999). Using web server logs in evaluating instructional websites. Journal of Educational Technology Systems, 28(2), 137-157.

Khine, M. S. (1996). The interaction of cognitive styles with varying levels of feedback in multimedia presentation. International Journal of Instructional Media, 23, 229-237.

Könings, K., Seidel, T., \& van Merriënboer, J. G. (2014). Participatory design of learning environments: integrating perspectives of students, teachers, and designers. Instructional Science, 42(1), 1-9. doi:10.1007/s11251-013-9305-2 
Laird, T. N., \& Kuh, G. (2005). Student Experiences With Information Technology And Their Relationship To Other Aspects Of Student Engagement. Research in Higher Education, 46(2), 211-233. doi:10.1007/s11162-004-1600-y

Lamont, A., \& Maton, K. (2010). Unpopular music: Beliefs and behaviours towards music in education. In R. Wright (Ed.), Sociology and Music Education (pp. 63-80). London: Ashgate.

Landriscina, F. (2013).Simulation and learning: A model-centered approach. NY: Springer.

Li, Q. (2007). Student and Teacher Views About Technology. Journal of Research on Technology in Education, 39(4), 377-397.

Lin, W., Alvarez, S. A., \& Ruiz, C. (2002). Efficient adaptive-support association rule mining for recommender systems. Data mining and knowledge discovery, 6(1), 83-105.

Margaryan, A., Littlejohn, A., \& Vojt, G. (2011). Are digital natives a myth or reality? University students’ use of digital technologies. Computers \& Education, 56(2), 429440.

Merceron, A., \& Yacef, K. (2010). Measuring correlation of strong symmetric assocation rules in educational data. In C. Romero, S. Ventura, M. Pechenizkiy, \& R. S. J. D. Baker (Eds.), Handbook of Educational Data Mining (pp. 245-255). Boca Raton: Taylor \& Francis Group.

Messick, S. (1987). Structural relationships across cognition, personality, and style. Aptitude, Learning, and Instruction, 3, 35-75.

Mohamad, S. K., \& Tasir, Z. (2013). Educational data mining: A review. Procedia-Social and Behavioral Sciences, 97, 320-324.

Morgan, H. (1997). Cognitive styles and classroom learning. Westport, CT: Praeger. 
National Assessment Program. (2013). NAPLAN. Retrieved March 4, 2016, from http://www.nap.edu.au/naplan/naplan.html

Nisbet, R., Elder, J., \& Miner, G. (2009). Handbook of statistical analysis and data mining applications. NY: Elsevier.

OECD. (2006). PISA 2006 Information and Communication Technology Questionnaire. OECD Program for International Student Assessment.

Pellas, N. (2014). The influence of computer self-efficacy, metacognitive self-regulation and self-esteem on student engagement in online learning programs: Evidence from the virtual world of Second Life. Computers in Human Behavior, 35, 157-170.

Perera, D., Kay, J., Koprinska, I., Yacef, K., \& Zaiane, O. R. (2009). Clustering and sequential pattern mining of online collaborative learning data. IEEE Transactions on Knowledge and Data Engineering, 21(6), 759-772.

Price, L. (2004). Individual differences in learning: Cognitive control, cognitive style, and learning style. Educational Psychology, 24(5), 681-698.

Rittschof, K. A. (2010). Field dependence-independence as visuospatial and executive functioning in working memory: Implications for instructional systems design and research. Educational Technology Research and Development, 58(1), 99-114.

Romero, C., Ventura, S., Pechenizkiy, M., \& Baker, R. S. J. D. (2010). Handbook of educational data mining. Boca Raton: Taylor \& Francis Group.

Romero, C., \& Ventura, S. (2007). Educational data mining: A survey from 1995 to 2005. Expert systems with applications, 33(1), 135-146. 
Romero, C., \& Ventura, S. (2010). Educational data mining: a review of the state of the art. Systems, Man, and Cybernetics, Part C: Applications and Reviews, IEEE Transactions on, 40(6), 601-618.

Selwyn, N. (2009). Faceworking: exploring students’ education-related use of Facebook. Learning, Media and Technology, 34(2), 157-174. doi:10.1080/17439880902923622

Skryabin, M., Zhang, J., Liu, L., \& Zhang, D. (2015). How the ICT development level and usage influence student achievement in reading, mathematics, and science. Computers \& Education, 85, 49-58.

Tang, T., \& McCalla, G. (2005). Smart recommendation for an evolving e-learning system. International Journal on E-Learning, 4(1), 105-129.

Thompson, P. (2013). The digital natives as learners: Technology use patterns and approaches to learning. Computers \& Education, 65, 12-33.

Vermunt, J. D., \& Verloop, N. (1999). Congruence and friction between learning and teaching. Learning and Instruction, 9(3), 257-280.

Wang, S.-K., Hsu, H.-Y., Campbell, T., Coster, D., \& Longhurst, M. (2014). An investigation of middle school science teachers and students use of technology inside and outside of classrooms: considering whether digital natives are more technology savvy than their teachers. Educational Technology Research and Development, 62(6), 637-662.

Warschauer, M., \& Matuchniak, T. (2010). New technology and digital worlds: Analyzing evidence of equity in access, use, and outcomes. Review of Research in Education, 34(1), $179-225$. 
Witkin, H. A., Moore, C. A., Goodenough, D. R., \& Cox, P. W. (1977). Field-dependent and field-independent cognitive styles and their educational implications. Review of Educational Research, 47(1) 1-64.

Witkin, H. A., Oltman, P. K., Raskin, E., \& Karp, S. A. (1971). Manual for embedded figures test, children's embedded figures test, and group embedded figures test. Palo Alto, CA: Consulting Psychologists Press.

Witten, I. H., Frank, E., \& Hall, M. A. (2011). Data mining: Practical machine learning tools and techniques. New York: Elsevier.

Zaiane, O., \& Luo, J. (2001). Web usage mining for a better web-based learning environment. In Proceedings of the Conference on Advanced Technology for Education, Banff, Alberta (pp. 60-64). 


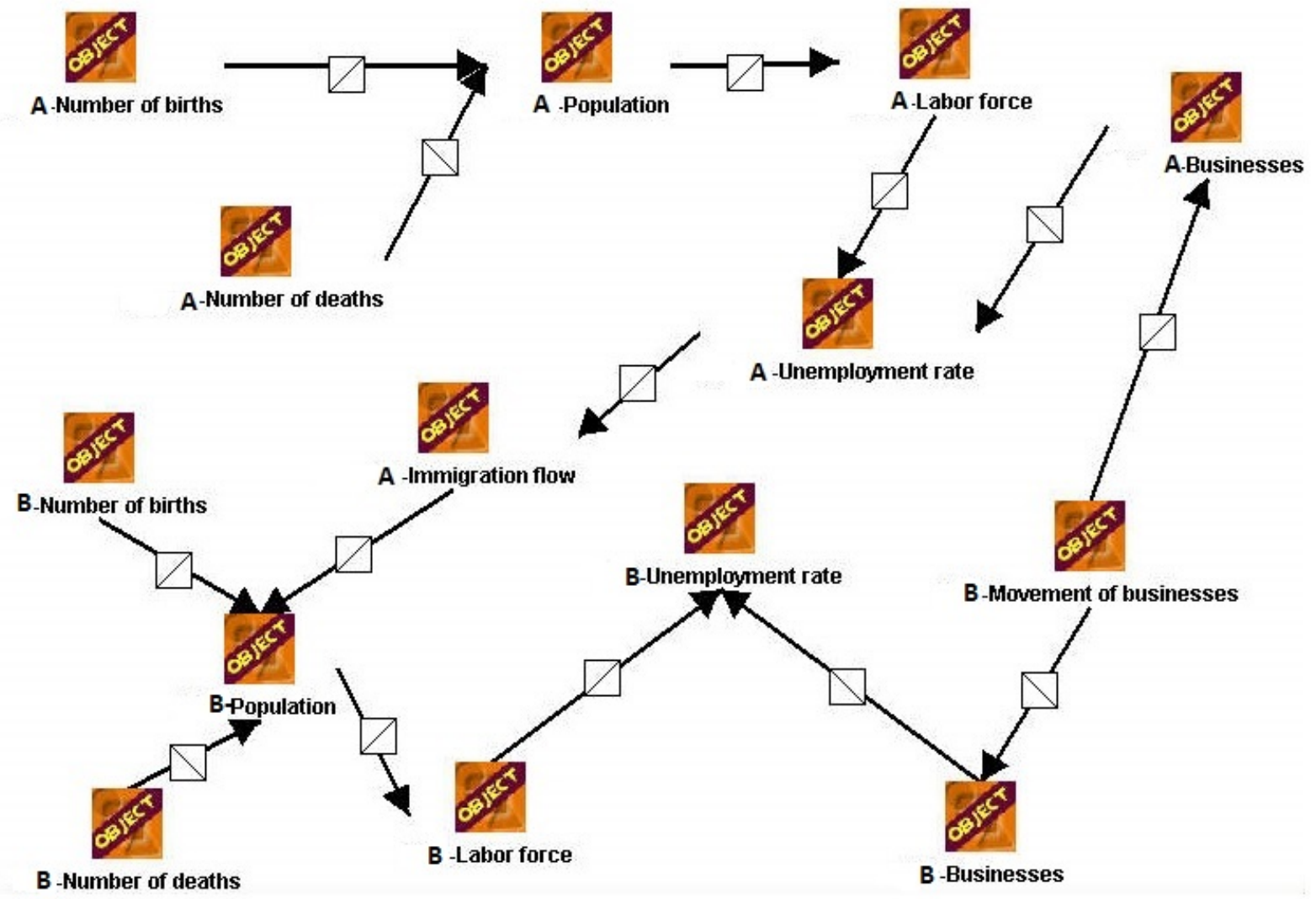

Figure 1. The underlying model about immigration policy of the glass-box simulation 


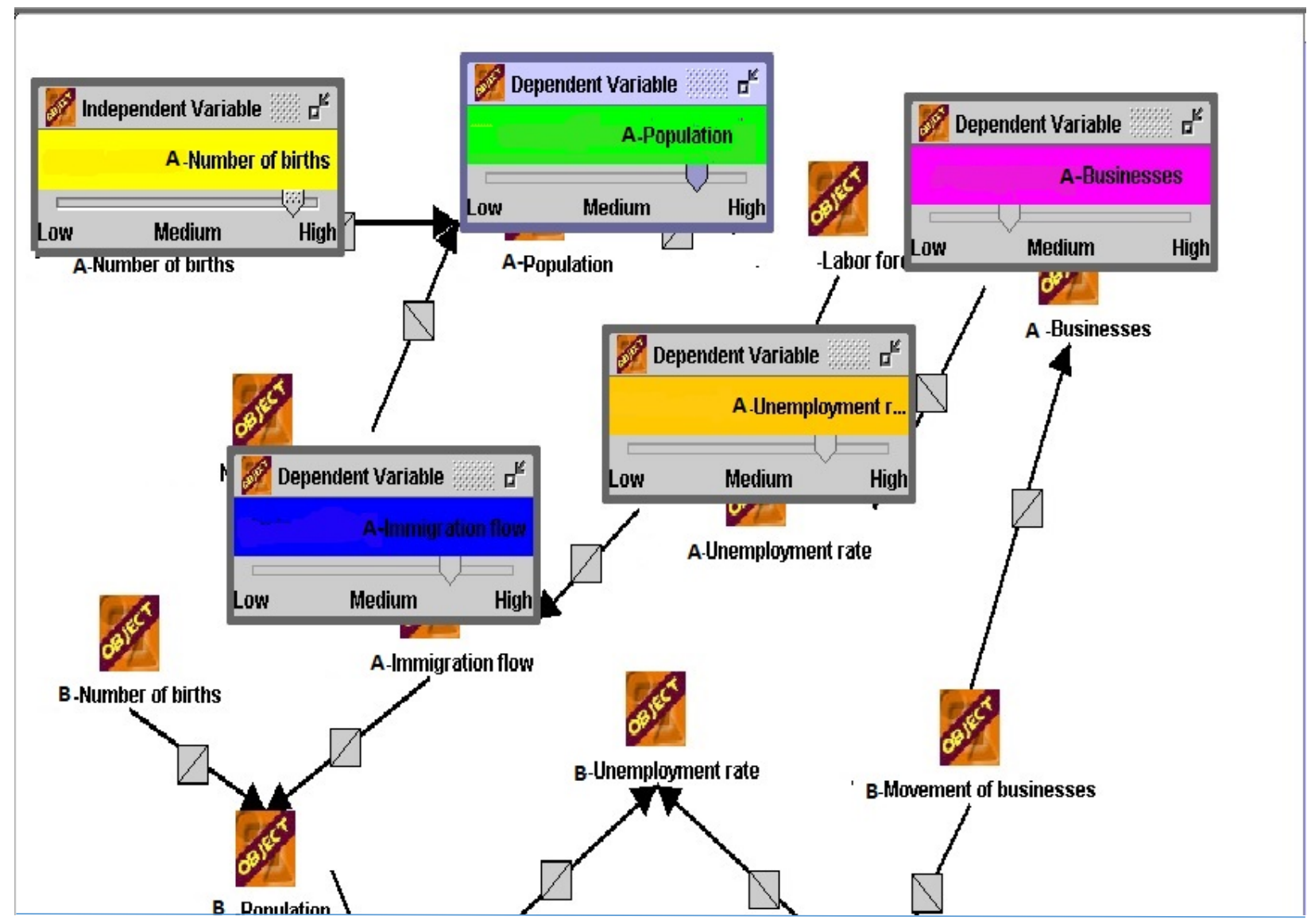

Figure 2. Simulation run 


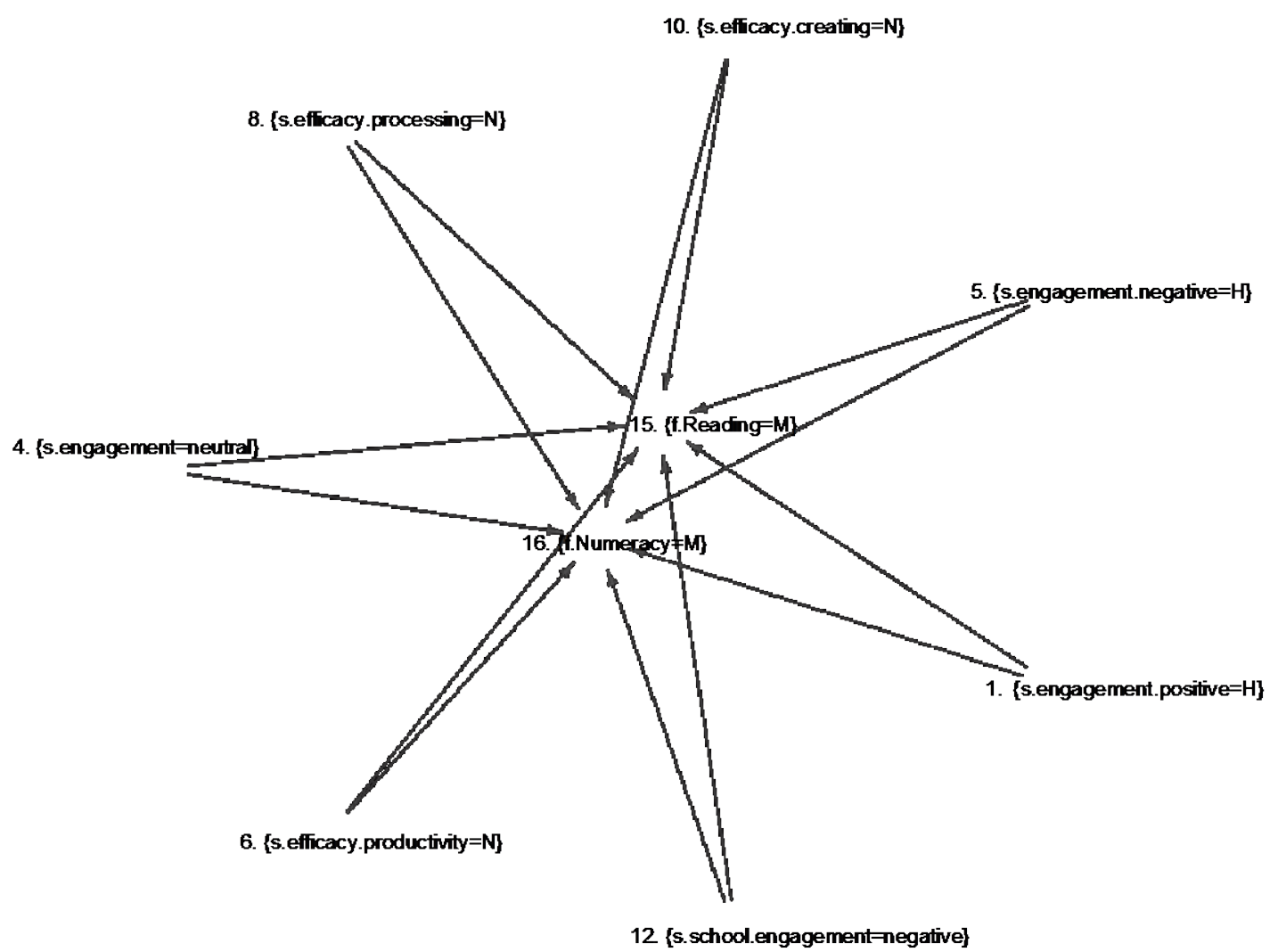

Figure 3. Positive ICT engagement 


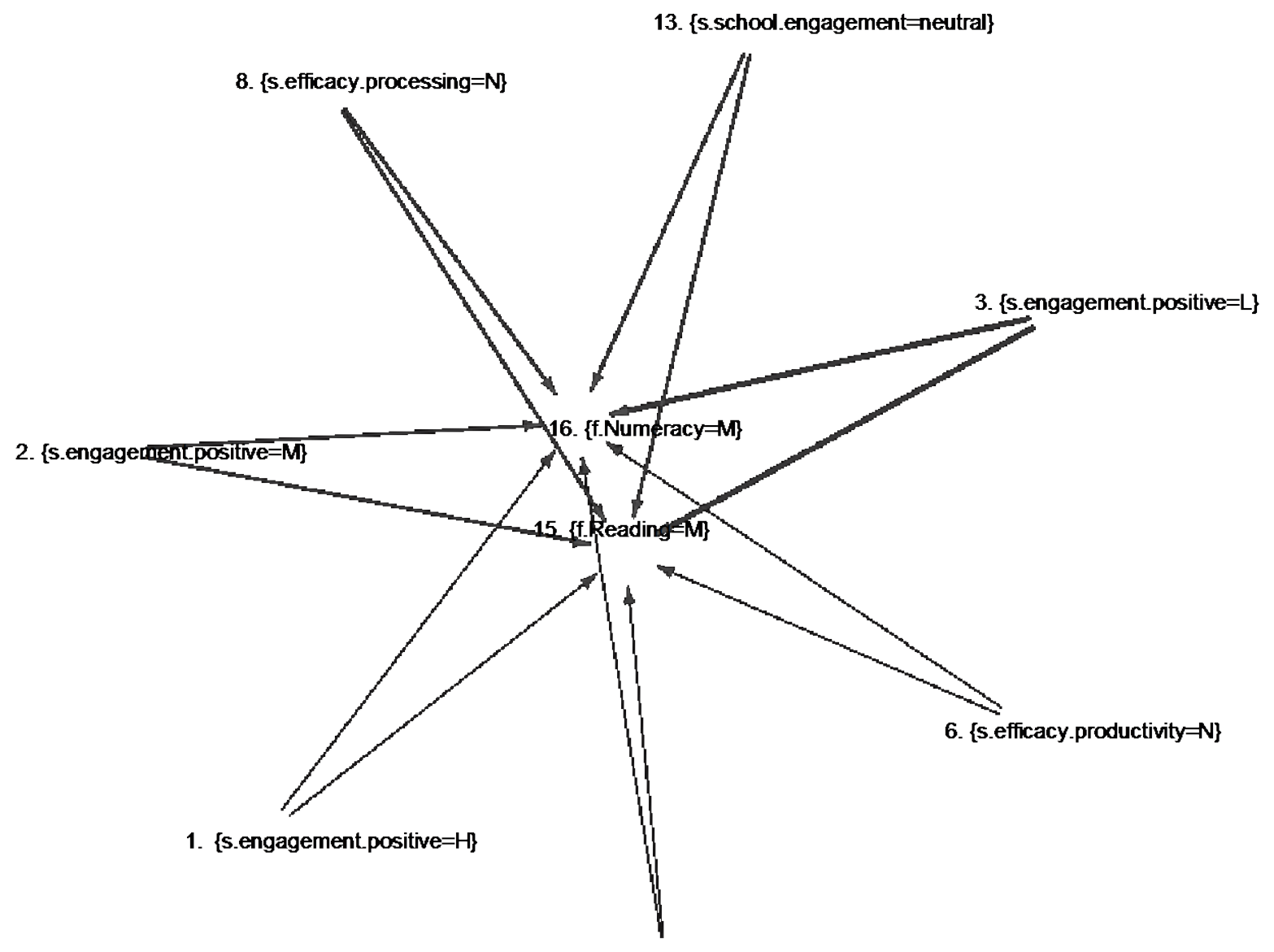

10. $\{$ s.efficacy.creating $=\mathrm{N}$ \}

Figure 4. Negative ICT engagement 
Table 1. Rubric for assessing the quality of learners' answers

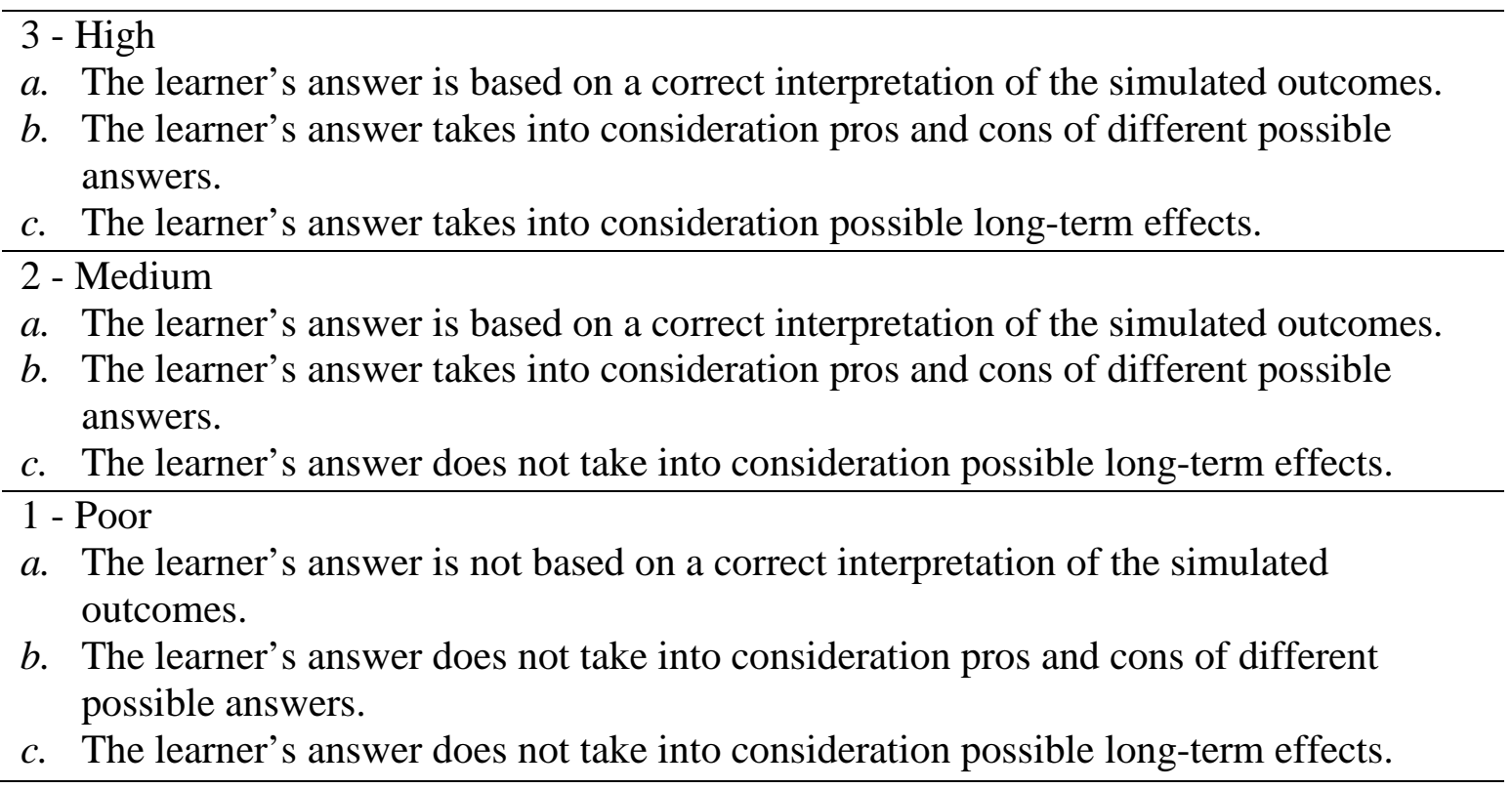


Table 2. Sequential rules for FD learners

\begin{tabular}{|c|c|c|c|c|c|}
\hline Antecedent & $==>$ & Consequent & Antecedent & $==>$ & Consequent \\
\hline 1. (B), (B) & $==>$ & $(\mathrm{T})$ & 7. (B), (B), (T), (P) & $==>$ & $(\mathrm{S})$ \\
\hline 2. (B), (B) & $==>$ & $(\mathrm{M})$ & 8. (B), (B) & $==>$ & $(\mathrm{T}),(\mathrm{S})$ \\
\hline 3. (B), (B) & $==>$ & $(\mathrm{P})$ & 9. (B), (B) & $==>$ & $(\mathrm{M}),(\mathrm{P})$ \\
\hline 4. (B), (B), (T) & $==>$ & (M) & 10. (B), (B), (M), (P) & $==>$ & (S) \\
\hline $\begin{array}{l}\text { 5. (B), (B), (T), } \\
(\mathrm{M})\end{array}$ & $==>$ & (S) & 11. (B) & $==>$ & (T), (P) \\
\hline \multirow[t]{2}{*}{ 6. (B), (B), (T) } & $==>$ & $(\mathrm{P})$ & 12. (B), (T), (M) & $==>$ & (P), (IV2) \\
\hline & & & 13. (B), (T), (M) & $==>$ & (P), (IV1) \\
\hline
\end{tabular}

Note: B: BUILD; T: TEST; M: METER; P: PLAY; S: STOP; IV1 = Country A-Number of births; IV2 = Country B-Movement of businesses. 
Table 3. Frequent sequences of rules for FD learners

Frequent Sequences

Frequency

( B ), ( B ), ( T )

70,00

( B ), ( B ), ( M )

70,00

( $\mathrm{B}),(\mathrm{B}),(\mathrm{P})$

70,00

( $\mathrm{B}),(\mathrm{B}),(\mathrm{T}),(\mathrm{M})$

70,00

( $\mathrm{B}),(\mathrm{B}),(\mathrm{T}),(\mathrm{P})$

70,00

( B ), ( B ), ( T ), ( M ), ( S )

70,00

( $\mathrm{B}),(\mathrm{T}),(\mathrm{P})$

70,00

( B ), ( B ), ( T ), ( P ), ( S )

70,00

( B ), ( B ), ( T ), ( S )

70,00

( $\mathrm{B}),(\mathrm{B}),(\mathrm{M}),(\mathrm{P})$

70,00

( B ), ( B ), ( M ), ( P ), ( $\mathrm{S})$

70,00

( B ), ( T ), ( M ), ( P ), ( IV1 )

46,00

( B ), ( T ), ( M ), ( P ), ( IV2 )

39,00

Note: B: BUILD; T: TEST; M: METER; S: STOP; P: PLAY; IV1 = Country A-Number of births; IV2 = Country B-Movement of businesses. 
Table 4. Sequential rules for FI learners

\begin{tabular}{|c|c|c|c|c|c|}
\hline Antecedent & $==>$ & Consequent & Antecedent & $==>$ & Consequent \\
\hline 1. (B), (T), (M), (P) & $==>$ & (IV1) & $\begin{array}{l}\text { 13. (B), (T), (M), (P), } \\
\text { (IV1) }\end{array}$ & $==>$ & (IV2), (IV3) \\
\hline 2. (B), (T), (M), (P) & $==>$ & (IV2) & $\begin{array}{l}\text { 14. (B), (T), (M), (P), } \\
\text { (IV2) }\end{array}$ & $==>$ & (IV3) \\
\hline 3. (B), (T), (M), (P) & $==>$ & (IV3) & $\begin{array}{l}\text { 15. (B), (T), (M), (P), } \\
\text { (IV1) }\end{array}$ & $==>$ & (IV2), (IV4) \\
\hline 4. (B), (T), (M), (P) & $==>$ & (IV4) & $\begin{array}{l}\text { 16. (B), (T), (M), (P), } \\
\text { (IV1), (IV3) }\end{array}$ & $==>$ & (IV4) \\
\hline 5. (B), (T), (M), (P) & $==>$ & (IV5) & $\begin{array}{l}\text { 17. (B), (T), (M), (P), } \\
\text { (IV1) }\end{array}$ & $==>$ & (IV2), (IV5) \\
\hline 6. (B), (T), (M), (P) & $==>$ & (IV1), (IV2) & $\begin{array}{l}\text { 18. (B), (T), (M), (P), } \\
\text { (IV1), (IV3) }\end{array}$ & $==>$ & (IV5) \\
\hline $\begin{array}{l}\text { 7. (B), (T), (M), (P), } \\
\text { (IV1) }\end{array}$ & $==>$ & (IV5) & $\begin{array}{l}\text { 19. (B), (T), (M), (P), } \\
\text { (IV1) }\end{array}$ & $==>$ & (IV4), (IV5) \\
\hline 8. (B), (T), (M), (P) & $==>$ & (IV1), (IV3) & $\begin{array}{l}\text { 20. (B), (T), (M), (P), } \\
\text { (IV4) }\end{array}$ & $==>$ & (IV5) \\
\hline $\begin{array}{l}\text { 9. (B), (T), (M), (P), } \\
\text { (IV1) }\end{array}$ & $==>$ & (IV2), (IV5) & $\begin{array}{l}\text { 21. (B), (T), (M), (P), } \\
\text { (IV2) }\end{array}$ & $==>$ & (IV5) \\
\hline 10. (B), (T), (M) (P) & $==>$ & (IV1), (IV4) & $\begin{array}{l}\text { 22. (B), (T), (M), (P), } \\
\text { (IV3) }\end{array}$ & $==>$ & (IV4) \\
\hline 11. (B), (T), (M), (P) & $==>$ & (IV1), (IV5) & $\begin{array}{lll}\begin{array}{l}23 . \\
\text { (P),(IV3) }\end{array} & (\mathrm{T}), \quad(\mathrm{M}), \\
\end{array}$ & $==>$ & (IV5) \\
\hline 12. (B), (T), (M), (P) & $==>$ & (IV2), (IV4) & & & \\
\hline
\end{tabular}

Note: B: BUILD; T: TEST; M: METER; P: PLAY; IV1 = Country A-Number of births; IV2 = Country B-Movement of businesses; IV3 = Country A-Number of deaths; IV4 = Country BNumber of births; IV5 = Country B-Number of deaths. 
Table 5. Frequent sequences of rules for FI learners

\begin{tabular}{ll}
\hline & \\
Frequent sequences & Frequency \\
& \\
\hline & \\
( B ), ( T ), ( M ), ( P ), ( IV1 ) & 45,00 \\
( B ), ( T ), ( M ), ( P ), ( IV2 ) & 45,00 \\
( B ), ( T ), ( M ), ( P ), ( IV3 ) & 45,00 \\
( B ), ( T ), ( M ), ( P ), ( IV4 ) & 45,00 \\
( B ), ( T ), ( M ), ( P ), ( IV5 ) & 45,00 \\
( B ), ( T ), ( M ), ( P ), ( IV1 ), ( IV2 ) & 30,00 \\
( B ), ( T ), ( M ), ( P ), ( IV1 ), ( IV3 ) & 30,00 \\
( B ), ( T ), ( M ), ( P ), ( IV1 ), ( IV4 ) & 30,00 \\
( B ), ( T ), ( M ), ( P ), ( IV1 ), ( IV5 ) & 30,00 \\
( B ), ( T ), ( M ), ( P ), ( IV2 ), ( IV3 ) & 30,00 \\
( B ), ( T ), ( M ), ( P ), ( IV2 ), ( IV4 ) & 30,00 \\
( B ), ( T ), ( M ), ( P ), ( IV2 ), ( IV5 ) & 30,00 \\
( B ), ( T ), ( M ), ( P ), ( IV3 ), ( IV4 ) & 30,00 \\
( B ), ( T ), ( M ), ( P ), ( IV3 ), ( IV5 ) & 30,00 \\
( B ), ( T ), ( M ), ( P ), ( IV4 ), ( IV5 ) & 30,00 \\
( B ), ( T ), ( M ), ( P ), ( IV1 ), ( IV2 ), ( IV3 ) & 30,00 \\
( B ), ( T ), ( M ), ( P ), ( IV1 ), ( IV2 ), ( IV4 ) & 30,00 \\
( B ), ( T ), ( M ), ( P ), ( IV1 ), ( IV2 ), ( IV5 ) & 30,00 \\
( B ), ( T ), ( M ), ( P ), ( IV1 ), ( IV3 ), ( IV4 ) & 30,00 \\
( B ), ( T ), ( M ), ( P ), ( IV1 ), ( IV3 ), ( IV5 ) & 30,00 \\
( B ), ( T ), ( M ), ( P ), ( IV1 ), ( IV4 ), ( IV5 ) & 30,00 \\
\end{tabular}

Note: B: BUILD; T: TEST; M: METER; P: PLAY; IV1 = Country A-Number of births; IV2 = Country B-Movement of businesses; IV3 = Country A-Number of deaths; IV4 = Country BNumber of births; IV5 = Country B-Number of deaths. 
Table 6. Key factors and their descriptions

\begin{tabular}{|c|c|c|}
\hline Factor & Description & Sample items \\
\hline $\begin{array}{l}\text { ICT } \\
\text { Engagement }\end{array}$ & $\begin{array}{l}\text { Includes } 4 \text { general } \\
\text { engagement items: each has } \\
4 \text { meaningful responses }{ }^{\mathrm{a}}\end{array}$ & $\begin{array}{l}\text { It is very important to me to work with a } \\
\text { computer. }\end{array}$ \\
\hline $\begin{array}{l}\text { Computer- } \\
\text { Efficacy }\end{array}$ & $\begin{array}{l}\text { Includes } 10 \text { items: } \\
\text { Productivity tasks (6), } \\
\text { Processing tasks (2) and } \\
\text { Creating tasks (2); each had } \\
4 \text { meaningful responses }{ }^{\text {b }}\end{array}$ & $\begin{array}{l}\text { Productivity: I am able to take notes using a } \\
\text { computer (e.g., recording notes in class). } \\
\text { Processing: I am able to edit written work } \\
\text { using a computer (e.g., revising writing, spell } \\
\text { checking, etc.). } \\
\text { Creating: I am able to write a first draft using } \\
\text { a computer (e.g., writing in Word rather than } \\
\text { on paper first). }\end{array}$ \\
\hline $\begin{array}{l}\text { School } \\
\text { Engagement }\end{array}$ & $\begin{array}{l}\text { Includes } 5 \text { items; each has } 4 \\
\text { responses }^{\text {a }}\end{array}$ & $\begin{array}{l}\text { In my school, I am treated with respect by } \\
\text { other students. }\end{array}$ \\
\hline $\begin{array}{l}\text { Learning } \\
\text { Preferences }\end{array}$ & $\begin{array}{l}\text { Includes } 3 \text { items: direct, self- } \\
\text { paced and collaborative } \\
\text { learning; each has } 4 \\
\text { meaningful responses }^{\mathrm{a}}\end{array}$ & $\begin{array}{l}\text { I learn more when the teacher talks to the class } \\
\text { (e.g., a History lecture, explaining Maths on } \\
\text { the board, etc.). } \\
\text { I learn more when I am able to explore ideas } \\
\text { on my own (e.g., independent research, doing } \\
\text { homework, etc.). } \\
\text { I learn more when I work in groups with other } \\
\text { students (e.g., on a problem set, on a project, } \\
\text { etc.). }\end{array}$ \\
\hline $\begin{array}{l}\text { Learning } \\
\text { Beliefs }\end{array}$ & $\begin{array}{l}\text { Includes } 3 \text { beliefs; self, } \\
\text { collaborative and instructed; } \\
\text { each has } 4 \text { meaningful } \\
\text { responses }^{\text {a }}\end{array}$ & $\begin{array}{l}\text { The things I learn in school will prepare me for } \\
\text { life as an adult. } \\
\text { I am able to contribute when working with } \\
\text { other students in a group. } \\
\text { I am encouraged to think about things in my } \\
\text { own way. }\end{array}$ \\
\hline $\begin{array}{l}\text { ICT } \\
\text { Importance in } \\
\text { Subject Areas } \\
\text { Teacher } \\
\text { Directed ICT }\end{array}$ & $\begin{array}{l}\text { Includes } 7 \text { school subjects; } \\
\text { each has } 4 \text { meaningful } \\
\text { responses }{ }^{\mathrm{d}} \\
\text { Includes } 10 \text { items: each has } 9 \\
\text { meaningful responses }{ }^{\mathrm{c}}\end{array}$ & $\begin{array}{l}\text { How important is it to use computers and ICTs } \\
\text { in...English, History, Geography. } \\
\text { Gather information from different places to } \\
\text { solve a problem (e.g., different websites or }\end{array}$ \\
\hline
\end{tabular}


Use

ICT Learning

Performance

NAPLAN

Reading

NAPLAN

Numeracy databases); 2-4 times a week.

My work is more creative when I use a computer.

Identify the main idea of the poem

Find value of missing angle in a triangle, with access to a calculator.

\footnotetext{
${ }^{\mathrm{a}} 4$ = Strongly agree, 3 = Agree, 2 = Disagree, 1 = Strongly disagree

${ }^{\mathrm{b}} 4$ = I can do this well by myself, 3 = I can do this with help from someone, 2 = I know what this is but can't do it, 1 = I don't know what this means

${ }^{\mathrm{c}} 8$ = Many times a day, $7=$ Once a day, $6=2-4$ times a day, $5=$ Once a week, $4=1-3$ times a month, $3=$ Once a term, 2 = 1-3 times a year, $1=$ Never, $0=$ I don't know what this means

${ }^{\mathrm{d}} 4$ = Very important, 3 = Important, 2 = Not very important, $1=$ Not at all
} 